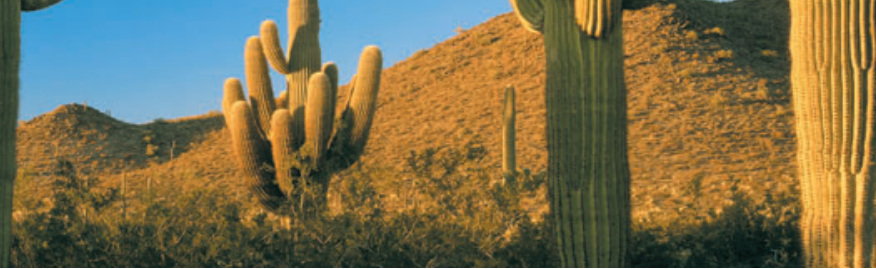

National Park Service

\title{
Effects of Post-Wildfire Sedimentation on Leopard Frog Habitat in Saguaro National Park
}

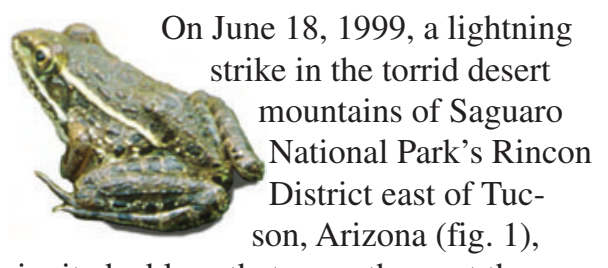

ignited a blaze that, over the next three weeks, would burn 6,500 acres of dry scrub and oak and pine forest. The most immediate and most obvious effect of the Box Canyon fire was the blackening of hillslopes, including the charring of hundreds of saguaro cacti, the giant succulent for which the park is named. The fire, however, also caused changes to the hydrologic system that would soon threaten other park resources, including the habitat of the increasingly scarce lowland leopard frog (fig. 2).

In Loma Verde Wash, an ephemeral stream that drains the northwest corner of the park, small basins within the bedrock channel bottoms collect rainwater and, in some cases, spring water that provide habitat for the leopard frog. Pools, known as tinajas, that contain water year round are of particular importance to the frogs' survival because they provide winter habitat for leopard frog tadpoles.

Runoff from the first rains following the Box Canyon fire carried large amounts of ash to ephemeral stream channels of Loma Verde Wash that left the waters in the pools inky black and greatly raised water temperatures. Although the stew of chemicals found in wildfire residue may have had some detrimental effects on the leopard frogs and other aquatic creatures, subsequent flows flushed the ash from the pools and a breeding population continued in the wash. Less than 2 years after the fire, however, a slug of gravel and coarse sand had made its way from the watershed slopes and headwaters into the uppermost pools, burying them to depths of 3 to 6 feet (fig. 3). Within 3 years after the fire, all but a few of the 32 pools in which leopard frogs had been observed were buried in sediment. All 24 pools that had been identified as breeding pools were buried and remained so as of summer 2005.

Habitat destruction and the introduction of non-native species throughout the Tucson Basin have reduced the once-abundant leopard frogs' range to a few isolated canyons, including several in Saguaro National Park. This species has likewise been extirpated from many other areas in Arizona and from approximately half its range in the United States. The wide-scale disappearance of the lowland leopard frog has led to its classification as a Priority Vulnerable Species in the Sonoran Desert Conservation Plan implemented by Pima County in Arizona and

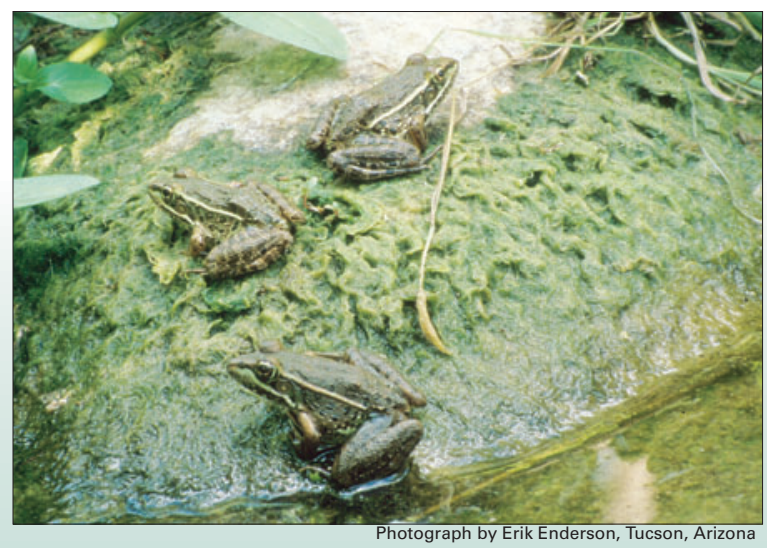

Figure 2. The lowland leopard frog's population in Saguaro National Park Rincon District is dependent on perennial pools of water in bedrock basins.

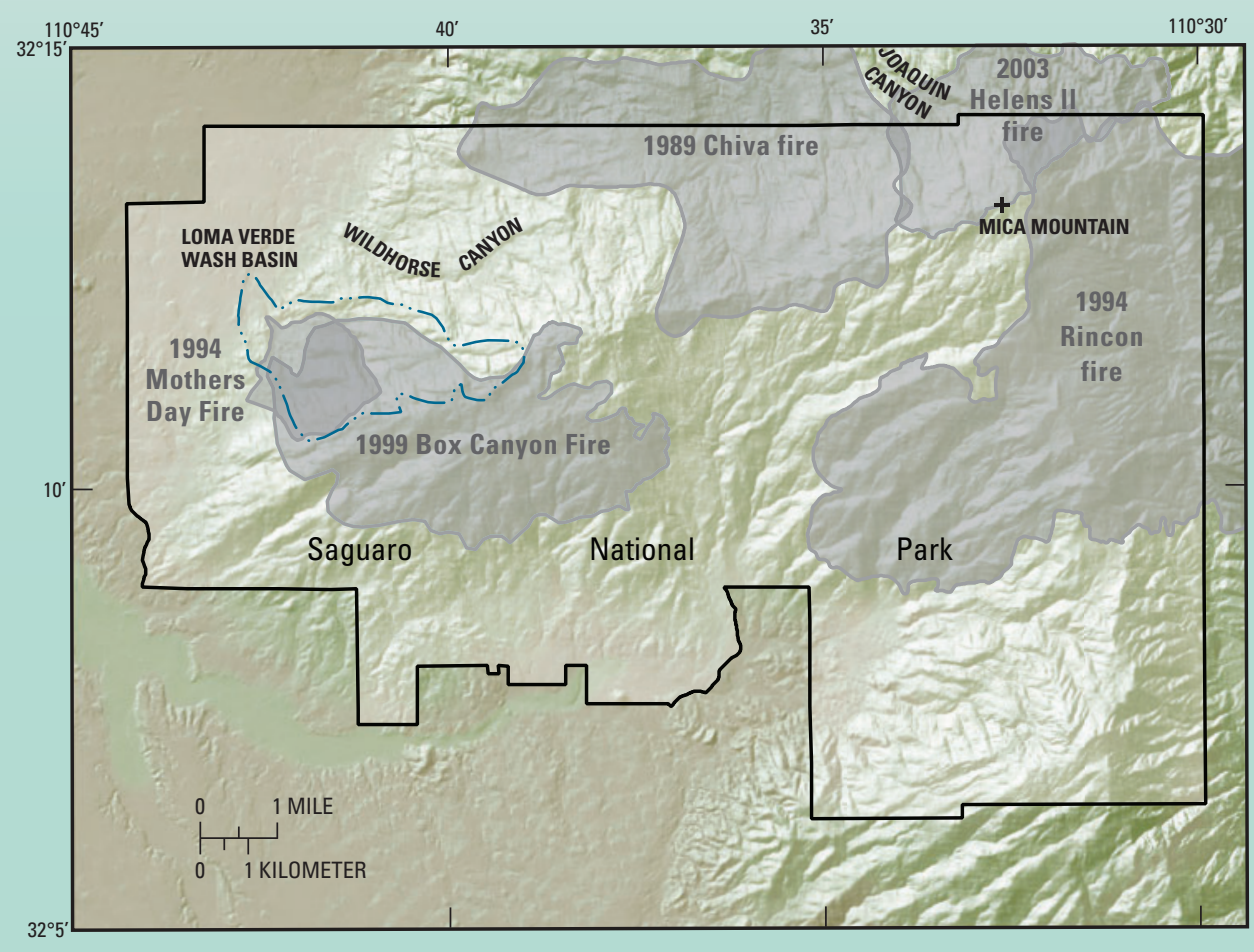

Figure 1. Saguaro National Park (black boundary) and extent of major fires occurring since 1989. 

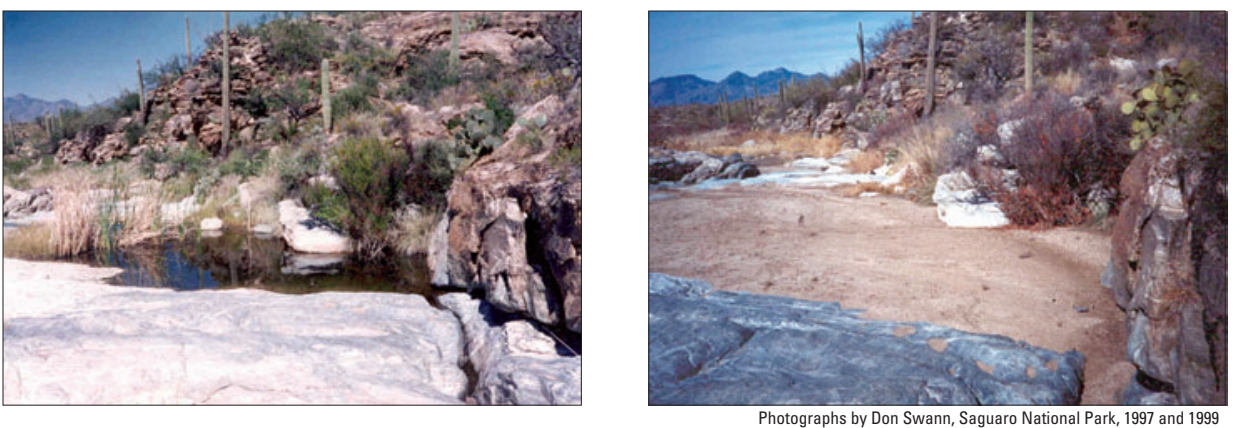

Figure 3. A tinaja in Loma Verde Wash before (left) and several months after (right) the Box Canyon fire of 1999. Within 2 years of the fire, all of the tinajas downstream from this one had filled with sand.

gists to the hazard presented by excessive sedimentation in the wake of wildfires. While conducting inventories of aquatic habitat, park biologists also discovered that a large pool in Wildhorse Canyon Wash, downstream from the 1989 Chiva fire, had filled with sediment at some unknown date. Sixteen years after the fire, the pool remains filled.

\section{Wildfire Management}

These discoveries have important implications for Park Service fire management policies, which are intended to establish a natural fire regimen in Saguaro National Park by prescribed burning and by selective suppression of naturally caused fires. Fire is a critical component of the dry oak and pine forests of Arizona. Frequent, naturally caused fires keep forest floors clear of heavy accumulations of woody vegetation, leaf and pine litter, dead trees and branches, and of overly dense forest stands, all of which can otherwise be fuel sources for much larger, stand-destroying fires. Fire management practices of the 20th century, which involved suppression of most fires throughout the Western United States, have left many forests with high fuel loads that make them susceptible to intense and extensive runaway wildfires.

Within Saguaro National Park's Rincon District, a combination of factors, including past fire-management practices and high production of fuels during wet years followed by exceptionally dry years, has resulted in five hot, destructive wildfires covering about 40,000 acres in the past 16 years (fig. 1). Burn areas typically result in higher volumes of storm runoff compared to runoff in the same areas during pre-fire conditions. Higher stream runoff is accompanied by widespread erosion in upland areas and deposition of exceptional volumes of sediment in lowland areas.

The relation between wildfires and excessive sedimentation and the associated threat to the leopard frog can bring conflicting pressures on National Park Service fire management policies. Park managers are faced with the task of trying to reestablish and maintain a healthy, firedependent ecosystem at the same time they are trying to protect a dwindling population of frogs.

\section{Sedimentation Study Objectives}

To assist managers in the assessment of appropriate fire management practices for protecting aquatic habitat, the U.S. Geological Survey, in cooperation with the National Park Service, is conducting a study of hydrologic changes caused by uncontrolled wildfires and the effects of increased sediment transport and deposition on leopard frog habitat in the Rincon District of Saguaro National Park Objectives of the 3-year project include: (1) estimate the background rates of sedimentation in perennial bedrock pools within the study area and characterize the sediments in pools that presently provide adequate habitat for the leopard frog and other aquatic species as well as in pools that have been rendered unfit for habitat because of excessive sedimentation, (2) determine mechanisms of sediment delivery from burned areas and the change in sediment yields caused by burning of the watersheds, (3) determine source areas of excess sedimentation in burned areas and their physical characteristics, such as topography, geology, soil type and thickness, and effects of fire on soil properties, and (4) estimate potential sediment yield from unburned areas in the event of future uncontrolled fires.

\section{Physical Setting}

The Rincon District of Saguaro National Park encompasses about 105 square miles of rugged upland desert and mountainous terrain east of Tucson. Altitude ranges from about 2,500 feet along the western edge of the park to about 8,500 feet on several peaks in the Rincon Mountains. Most of the park is mountainous, but the most heavily visited areas are bajadas, landscape features formed by overlapping alluvial fans, along the base of the mountains at elevations between about 2,500 and 3,200 feet. The climate is semiarid with summer and winter rainy seasons. Average annual precipitation is about 12 inches per year near the base of the mountains and about 28 inches per year at the highest elevations, where some precipitation falls as snow.

The bajadas of the lower elevations are blanketed with Sonoran Desert vegetation, which includes extensive stands of saguaro cactus as well as an abundance of other cacti. With increasing elevation, the hillslopes are vegetated with grassland and scrubland, oak and juniper woodlands, juniper and piñon pine woodlands, Ponderosa pine forest, and mixed conifer forest.

The rocks of the Rincon Mountains are predominantly granitic, in many cases highly fractured and sheared, which weather to coarse, gravely sand that covers most hillslopes although steep slopes of exposed bedrock are common. The mountains are dissected by a dense drainage system of small, steep-gradient streams, most of which are ephemeral, flowing only in response to storms or periods of runoff. Stream channels change dramatically in physical characteristics as they cross over terrain of varying steepness and geology. Where channels drain slopes covered with unconsolidated materials, such as on soil-covered hillslopes and through the alluvial fan deposits of the bajadas, the channel banks typically are composed of uncemented to moderately cemented sand and gravel.

Many channel reaches cross outcrops of resistant bedrock. Tinajas, are found in these bedrock reaches and provide habitat for the lowland leopard frog. Tinajas range from about 3 to 30 feet in diameter. 


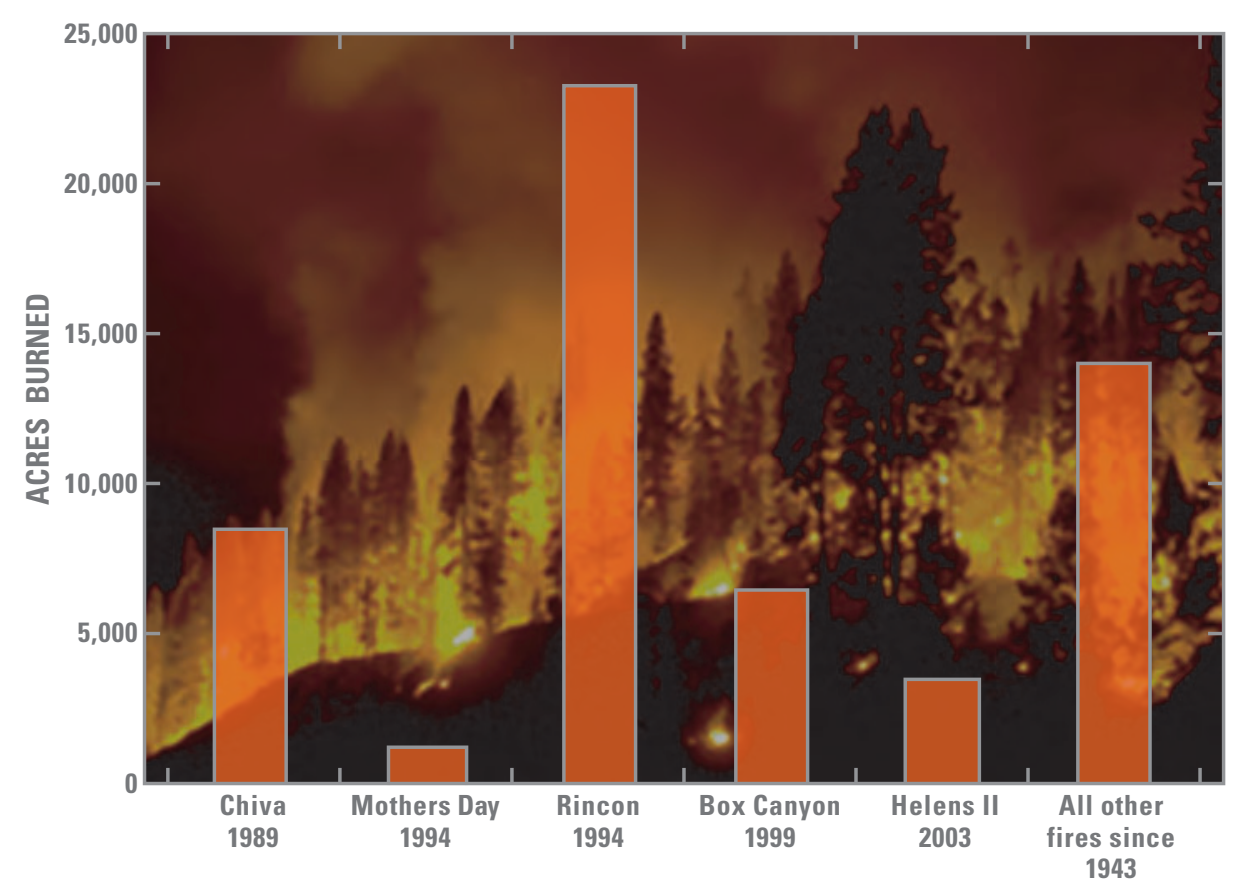

Figure 4. Fire history of Rincon District of Saguaro National Park since 1943.

\section{Fire History}

From 1943 through 2003, at least 40 fires affected over 57,000 acres in and adjacent to Saguaro National Park lands in the Rincon Mountains. Just six fires, however, burned about 92 percent of that total, and nearly 75 percent of the burned acreage was caused by five wildfires after 1988 (fig. 4). Of those recent fires, the Rincon fire of 1994 was by far the largest historical fire, burning about 23,300 acres in the park and in Coronado National Forest lands surrounding the park.

Burned acreage is based on the perimeter of the fire area and may include sizeable swaths of vegetation that are untouched by fire as well as many individual trees and other plants that are lightly burned and survive.

Fires have swept through nearly 40 percent of the park's forests, grasslands, and scrublands since 1989, burning about 50 percent of the forested areas and 35 percent of chaparral and desert scrublands and grasslands. The Chiva, Mothers Day, and Box Canyon fires accounted for most of the burned acreage in scrublands and grasslands, and the Rincon and Helens II fires primarily burned upper elevation forests and woodlands. Nearly the entire 1,000 acres of mixed conifer forest on Mica Mountain, the smallest vegetation zone in the park, was affected by the Helens II fire of 2003 (fig. 1). The north slope of Mica Mountain was particularly hard hit by the fire, which wreaked near-total destruction on many stands of Ponderosa pine and other conifers (fig. 5); however, other stands within the fire area were virtually untouched and many trees survived the fire despite charring of trunks and branches.

\section{Fire and Hydrology}

Sediment moves down hillslopes to enter stream channels by slow processes, such as soil creep in which sediment particles move gradually downhill under the force of gravity, or by faster processes, such as rill erosion or sheetwash in which sediment particles are entrained and transported by water flowing over the ground surface.

Once in the channel, sediment is moved downstream by streamflow. Along its course from upland basins to lowland valleys, sediment may be deposited as sand and gravel bars, on flood plains, or on the channel bottom. Such sediment is considered to be in storage and may be so for a period of hours to centuries depending on location and the magnitude of future streamflows.

A stream's ability to transport sediment depends on the strength of the streamflow and the size of the sediment particles. Coarse particles, such as pebbles, cobbles, and boulders, typically are deposited on the channel bottom where flows are swiftest, and fine sand and silt typically are deposited in quieter environments, such as flood plains or backwater pools. Under normal conditions, channels in the Rincon Mountains have little sediment in storage, and in steep reaches where they cut into solid bedrock there can be almost none.

Large, hot wildfires, however, alter watershed conditions in ways that can greatly increase the rate of sediment delivery to channels. The extensive destruction of vegetation from grasses to trees, as well as the layer of decaying leaves and conifer needles that comprise the forest litter, exposes the ground surface to direct effects of precipitation and storm runoff. Fires can burn into root systems that ordinarily bind soil to hillslopes, and finally, hot fires change the structure of the soil itself, making it resistant to infiltration from precipitation.

Such watershed changes accelerate the delivery of sediment to stream channels. The lack of vegetative cover and change in soil structure increase the amount of surface runoff in response to storms, resulting in fast-moving water with increased ability to erode and transport sediment on hillslopes. The low permeability of the soil and lack of a forest

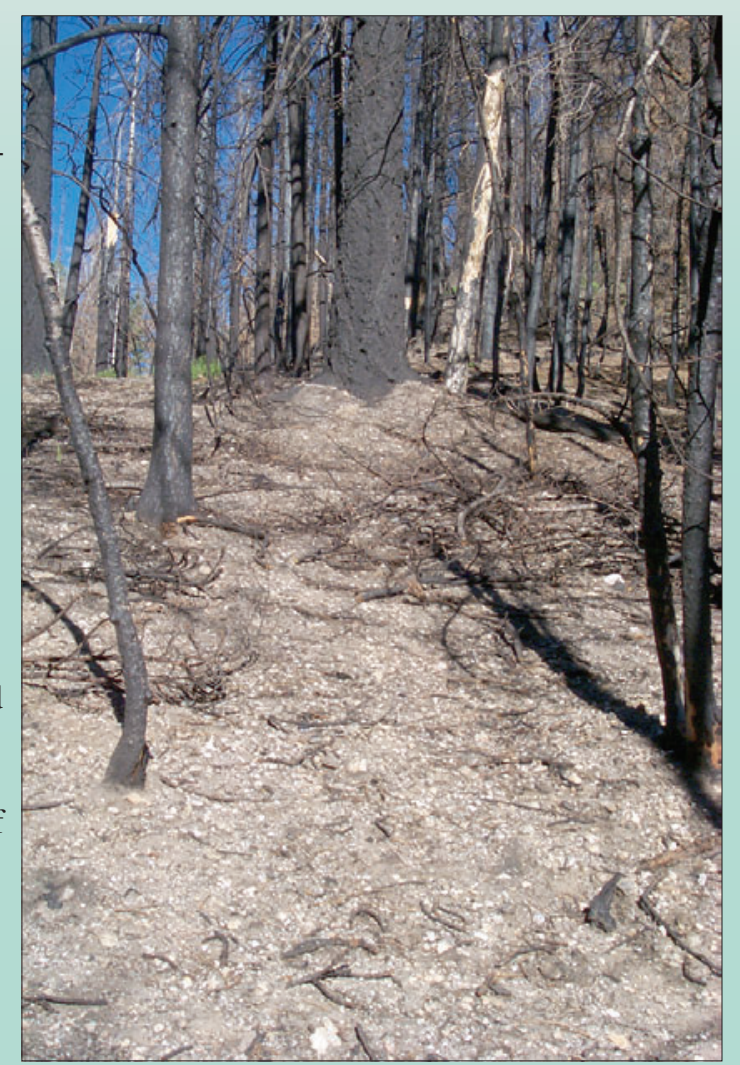

Figure 5. Mixed conifer forest on the north slope of Mica Mountain was destroyed by the Helens II fire in 2003. 
canopy to impede rainfall cause water to accumulate on the ground surface. This water then moves downstream as sheets of water (sheetwash erosion) or gathers in small streams that form rills and gullies. Under normal conditions, sheetwash and rill erosion are not significant processes on forested hillslopes, but after intense fires, the frequency and magnitude of such processes caused by watershed changes can persist for several years.

The increased transport of sediment from burned hillslopes can overwhelm the sediment-carrying capacity of a stream, resulting in excessive deposition of fresh sediment in stream channels. The amount of time the sediment remains stored in the channels depends on the volume of sediment available on hillslopes for transport, the period of time that is required for the conditions to stabilize on hillslopes, the frequency and size of streamflows available for scouring the sediment from the channel, and the physical characteristics of stream channels that govern the velocity of flows through a particular channel reach.

\section{Study Approaches}

The principal tasks needed to meet the objectives of the USGS study include a watershed analysis of the park's drainage basins, analysis of historical data, particularly photographs, field observations of erosion and sediment-transport mechanisms, and the changes in watershed conditions over the course of the study, and application of sediment erosion and transport rates in post-fire conditions determined from studies in other mountainous regions.

The watershed analysis involves the compilation of spatial data that are relevant to sediment transport. These include hillslope gradient, maximum elevation difference, channel density (total channel length per area), channel gradient, aspect, soil cover, vegetation cover, fire history, and fuel load. The analysis then is used to create an index of critical sediment-source areas most likely to produce excessive sedimentation in stream channels below the watershed.

Field observations include the mapping, photographing, and measurement of erosional features in recent burn areas and comparison with watershed conditions in older burn areas as well as mapping of sediment movement and storage in stream channels below burn areas. Sediment samples were collected from several depositional environments for particlesize analysis to assess the changes in sediment transport energies occurring in post-fire conditions on hillslopes and stream channels. Field observations and measurements of stream-channel physical properties are used to evaluate those pools that are most likely to be buried during episodes of extreme sedimentation and most likely to remain buried for sustained periods.

\section{Recent Observations}

The Helens II fire of 2003 occurred 1 year before the onset of this study and provided an opportunity to observe watershed conditions in the first several years following a major fire. The first field observations in the Helens II burn area were made in June 2004. Although summer-monsoon and winter precipitation had been below average following the fire, evidence of greater than normal sediment movement on the severely burned north hillslopes was plentiful, particularly from sheet wash erosion and accelerated soil creep. Sediment accumulation in the upstream reaches of channels appeared to be considerably greater in those channels below the burn area than in channels below unburned or lightly burned areas.

In the lower reaches of Joaquin Canyon north of the park boundary (fig. 1), ashy, fine-grained sediment that was flushed from the burned slopes in the first rains following the fire had been deposited on the channel bed and in bedrock pools. Although the bottoms and shoreline of some of the larger, water-filled pools were covered with black, ash-laden sediment, they still contained aquatic insects.

Following the light 2004 monsoon season, little change was observed in the Helens II burn area and in the channels of Joaquin Canyon below the burn area. The next visit took place in July 2005, following a slightly wetter than average winter. Fresh rills and gullies were noted on some of the steeper slopes in the burn area as well as small debris flows on some slopes. Debris flows are mass movements consisting of a slurry of water and sediment in which the sediment transported can range from the smallest clay, silt, and sand particles to boulders. On other slopes, however, dense stands of bracken fern appear to have begun stabilizing areas that had been subject to sheetwash erosion and some rill development in the first year after the fire (fig. 6).

In the Joaquin Canyon, meanwhile, at least one large pool was buried by as much as 3 feet of coarse sand between field visits made in September 2004 and June 2005. Pools downstream from the filled pool had received some coarse-sand deposition but were not yet filled.

Final field observations for this project were to be completed in fall 2005. The project will conclude by fall 2006.

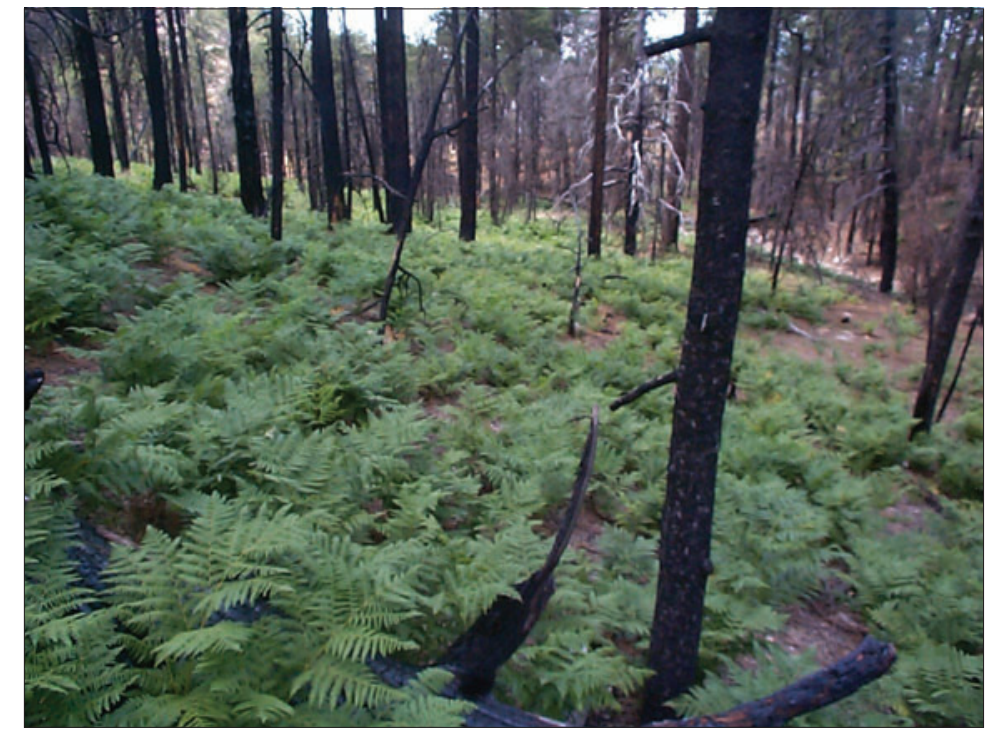

Figure 6. Bracken fern in the Helens II burn area on Mica Mountain has begun to stabilize soils on hillslopes two years after the fire, July 2005.
— John T.C. Parker

For additional information, please contact:

John T.C. Parker (jtparker@usgs.gov)

U.S. Geological Survey

520 North Park Avenue

Suite 221

Tucson, AZ 85719-5035

520-670-6671 